\title{
Perancangan dan Realisasi Sistem Kendali Lampu, Air Conditionerer Berbasis Android
}

\author{
Budiman Wibowo ${ }^{1}$, Hadian Satria Utama ${ }^{1}$, Nurwijayanti Kusumaningrum ${ }^{2}$
}

\begin{abstract}
In a house or building of course there is a room that will be filled in some facilities such as lights, air conditioners, and of course the door. This room is used to rest when it's tired to work all day, or used for other things that use a room. With the development of technology to date, of course these technologies increasingly pamper people in this world. When I was lying on the mattress, there must be a sense of laziness to move from the mattress when it wants to turn on the air conditioner, and even the lights that exist in the bedroom. For example when someone wants to sleep sometimes there is a sense of lazy just to turn off the lights (for people who prefer to sleep in the condition of the room without any lighting) or install a sleeping light that makes the bedroom is not too dark and also if there is someone who wants to go into the room of course there is a sense of laziness to unlock the door of the room, and there is also a door as a means to get in and out of the room itself. Therefore, a system is needed to control the lamp, air conditioner, and door lock by using a control device. This control device is an Android-based mobile phone and uses bluetooth connection. Users can turn on or off the existing lights in the bedroom and can adjust the brightness of the lights to be adjusted for people who want to sleep under what conditions in the room, other than that the user can also turn on or turn off the AC when it is outside the bedroom and can also open or lock the door lock.
\end{abstract}

KEYWORDS: Lamp, Air Condtioner, Door Lock, Arduino, Bluetooth

\begin{abstract}
ABSTRAK: Dalam sebuah rumah atau bangunan tentunya ada ruangan yang nantinya akan di isikan beberapa fasilitas seperti lampu, air conditioner, dan tentunya pintu. Ruangan ini biasa digunakan untuk beristirahat ketika sudah lelah bekerja seharian, atau digunakan untuk hal-hal lain yang menggunakan sebuah ruangan. Dengan berkembangnya teknologi hingga saat ini, tentunya teknologi-teknologi ini semakin memanjakan manusia di dunia ini. Ketika sudah berbaring di kasur, pasti ada rasa malas untuk beranjak dari kasur padahal ingin sekali untuk menyalakan air conditioner, mau pun lampu yang ada di dalam kamar tidur. Misalnya ketika seseorang ingin tidur kadang ada rasa malas hanya untuk mematikan lampu (bagi orang yang lebih suka tidur dalam kondisi ruangan tanpa ada pencahayaan) atau memasang lampu tidur yang membuat kamar tidur tidak terlalu gelap dan juga bila ada seseorang yang ingin masuk ke dalam kamar tentunya ada rasa malas untuk membuka kunci pintu kamar., dan juga terdapat pintu sebagai sarana untuk keluar masuk dari ruangan itu sendiri. Oleh karena itu, dibutuhkan sistem untuk mengendalikan lampu, air conditioner, dan kunci pintu itu dengan menggunakan sebuah alat kendali. Alat kendali ini berupa handphone berbasis Android dan menggunakan koneksi bluetooth. Pengguna dapat menyalakan atau mematikan lampu yang ada di dalam kamar tidur serta dapat mengatur brightness dari lampu itu untuk dapat disesuaikan bagi orang yang ingin tidur dalam kondisi seperti apa pada kamar itu, selain itu pengguna juga dapat menyalakan atau mematikan AC apabila sedang di luar kamar tidur dan juga dapat membuka atau mengunci kunci pintu.
\end{abstract}

KATA KUNCI: Lampu, Air conditioner, kunci pintu, Arduino, Bluetooth

\section{PENDAHULUAN}

$\mathrm{K}^{2}$ amar tidur adalah salah satu tempat yang paling private di dalam rumah. Kamar tidur biasa digunakan untuk beristirahat ketika sudah lelah bekerja seharian, selain itu kamar tidur juga biasa digunakan untuk belajar bagi para pelajar atau pun untuk ruangan bekerja pribadi agar tidak diganggu oleh orang lain. Tentunya di dalam satu kamar tidur ada beberapa fasilitas yang sudah pada umumnya, seperti lampu, air conditioner (AC), dan juga terdapat pintu sebagai sarana untuk keluar masuk dari ruangan itu sendiri.

Dengan berkembangnya teknologi hingga saat ini, tentunya teknologi-teknologi ini semakin memanjakan manusia di dunia ini. Ketika sudah berbaring di kasur, pasti ada rasa malas untuk beranjak dari kasur padahal ingin sekali untuk menyalakan air conditioner, mau pun lampu yang ada di dalam kamar tidur. Misalnya ketika seseorang ingin tidur kadang ada rasa malas hanya untuk mematikan lampu (bagi orang yang lebih suka tidur dalam kondisi ruangan tanpa ada pencahayaan) atau memasang lampu tidur yang membuat kamar tidur tidak terlalu gelap dan juga bila ada seseorang yang ingin masuk ke dalam kamar tentunya ada rasa malas untuk membuka kunci pintu kamar.

Permasalahan ini dapat ditanggulangi dengan mengganti sistem menyalakan lampu, AC dan membuka pintu yang secara manual menjadi sistem kendali lampu, AC, dan kunci pintu berbasis Android. Sistem ini menggunakan handphone berbasis Android sebagai alat kendalinya, dari handphone Android ini pengguna dapat menyalakan atau mematikan lampu yang ada di dalam kamar tidur serta dapat mengatur brightness dari lampu itu untuk dapat disesuaikan bagi orang yang ingin tidur dalam kondisi seperti apa pada kamar itu, selain itu pengguna juga dapat menyalakan atau mematikan AC apabila sedang di luar kamar tidur dan juga dapat membuka atau mengunci kunci pintu. Pengiriman data pada sistem ini akan melalui koneksi bluetooth.

Survei dilakukan sebanyak dua kali. Survei pertama dilakukan melalui studi pustaka berupa Jurnal TIAtma STMIK Atma Luhur Pangkalpinang yang berjudul Pengendalian Lampu Rumah Berbasis Mikrokontroler Arduino Menggunakan Smartphone Android yang di susun oleh Evan Taruna Setiawan. Sistem pengendali lampu rumah ini menggunakan internet sebagai media untuk pengiriman data. Sistem ini, user dapat melakukan input dari aplikasi kendali yang ada pada perangkat smartphone android. Tersedia dua macam pilihan input yaitu standar input (tombol on/off lampu) dan speech recognition. Penggunaan speech recognition membutuhkan koneksi internet. Data yang diinputkan berupa data serial yang dikirim ke mikrokontroler arduino melalui wifi. Data yang dikirim dari smartphone Android dan menggunakan internet. Data yang dikirim dari smartphone Android akan

\footnotetext{
${ }^{1}$ Program Studi Teknik Elektro, Fakultas Teknik Universitas Tarumanagara

${ }^{2}$ Program Studi Teknik Elektro Universitas Dirgantara Marsekal Suryadarma
} 
diterima oleh modul wifi yang terhubung pada sistem mikrokontroler arduino. Data serial tersebut diterjemahkan oleh mikrokontroler arduino menjadi data paralel. Data paralel yang dihasilkan oleh mikrokontroler arduino diteruskan ke relay melalui indikator LED yang berfungsi untuk memastikan apabila lampu hidup, maka LED juga akan hidup, begitu juga sebaliknya. Kemudian relay akan meneruskan data yang digunakan untuk menghidupkan atau mematikan lampu.

Survei kedua yaitu melihat jadwal penggunaan ruangan pada kelas-kelas yang terdapat di Jurusan Teknik Elektro dan Teknik Perancanaan Wilayah \& Kota . Kegiatan belajar ada yang berlangsung dari pagi hingga sore sedangkan ruang kelas L.4/09 memiliki jeda waktu tertentu dari pagi hingga sore. Jeda waktu tersebut membuat karyawan jurusan harus mematikan fasilitas lampu dan AC secara manual serta membuka dan mengunci pintu ketika kelas tidak digunakan secara manual juga.

\section{DESKRIPSI KONSEP}

Alat yang akan dirancang ini berfungsi untuk membantu pengguna atau penghuni kamar tidur dalam menyalakan atau mematikan lampu, air conditioner (AC), dan juga dapat membuka atau mengunci kunci pintu serta dapat mengatur brightness dari lampu sesuai keinginan pengguna dengan menggunakan aplikasi pada smartphone. Teknologi yang digunakan dalam sistem ini menggunakan smartphone yang berbasis Android dengan layar sentuh yang mudah digunakan. Dalam sistem ini juga terdapat aplikasi yang dapat digunakan oleh pengguna yang akan dijadikan sebagai user interface yang dapat menampilkan tombol-tombol virtual.

Dalam menghubungkan antara smartphone dan alat-alat yang tersedia seperti lampu, AC, dan kunci pintu dibutuhkan teknologi lain yang harus memiliki kemampuan untuk dapat dihubungkan tanpa menggunakan kabel, yaitu menggunakan teknologi bluetooth sebagai penerima dan pengirim sinyal input dari atau ke smartphone. Maka dari itu sistem ini menggunakan modul bluetooth untuk menghubungkan smartphone Android dengan alatalat tersebut.

Selain dari modul bluetooth dan user interface pada smartphone Android, sistem ini tidak dapat bekerja jika hanya menggunakan modul tersebut. Sistem ini membutuhkan modul pemroses. Modul pemroses ini dapat mengontrol modul infrared yang berfungsi sebagai remote untuk dapat mengontrol air conditioiner, modul relay yang nantinya akan mengontrol solenoid, dan juga modul AC light dimmer yang akan mengontrol lampu AC 220v.

Dalam user interface terdapat 3 buah kolom pilihan yang terdiri dari beberapa device yang dapat di kendalikan yaitu Lampu, Air Conditioner, dan Kunci Pintu. Pada kolom Kunci Pintu terdapat dua buat pilihan, on dan off. Apabila user menekan tombol on maka katup pada solenoid akan menutup, dan bila menekan tombol off maka katup pada solenoid akan membuka yang akan membuat pintu menjadi terkunci. Kemudian pada kolom Air Conditioner terdapat beberapa tombol, yaitu 1 tombol bersimbol on/off untuk menyalakan atau mematikan AC, tombol Temp Up untuk menaikan temperatur yang dihasilkan oleh AC, tombol Temp Down untuk menurunkan temperatur yang dihasilkan oleh AC, tombol Fan Speed yang berfungsi untuk mengatur kecepatan kipas yang dikeluarkan oleh AC, dan tombol Swing untuk dapat menggerakkan pengarah angin yang dihasilkan AC secara otomatis. Lalu juga terdapat kolom Lampu yang terdapat slider yang berfungsi untuk menyalakan atau mematikan lampu, serta dapat mengatur brightness dari lampu itu sendiri.

\section{CARA KERJA SISTEM}

Alat ini dapat bekerja ketika terdapat input dari pengguna. Input tersebut berasal dari smartphone Android yang ditekan oleh pengguna. Input tersebut akan mengirimkan data ke modul pemroses menggunakan jaringan bluetooth. Kemudian dari modul pemroses yang sudah diberi input sebelumnya dapat mengontrol lampu serta modul infrared yang mana pada sistem ini di jadikan sebagai remote controller untuk mengendalikan AC dan dapat menggerakkan modul relay yang dapat mengontrol modul kunci pintu. 


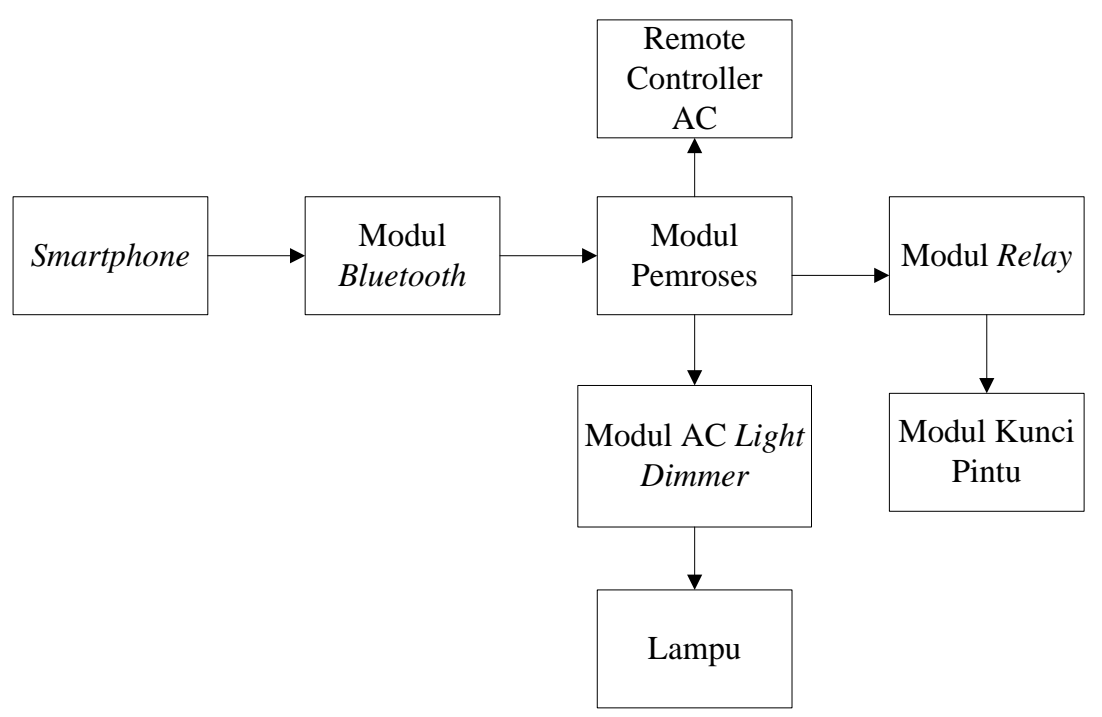

- Gambar 1. Diagram Blok Keseluruhan sistem

\section{MODUL MIKROKONTROLER ARDUINO MEGA 2560}

Arduino menyatakan perangkat lunak dan perangkat keras yang digunakan untuk mengontrol sejumlah perangkat elektronik. Ada berbagai jenis Arduino, salah satunya adalah Arduino Mega. Arduino Mega 2560 adalah sebuah modul mikrokontroler berbasis ATmega 2560. Dalam proses memasukkan program ke Arduino, Arduino tidak memerlukan bantuan dari modul lain seperti downloader. Proses memasukan program ke Arduino cukup dengan menggunakan kabel serial yang sudah disediakan.

Arduino Mega 2560 memiliki 54 pin digital yang dapat digunakan menjadi input maupun output. Selain pin digital, modul ini juga mempunyai 16 pin analog. Pin analog juga dapat digunakan sebagai keluaran atau masukan sinyal digital. Modul ini juga memiliki 4 pasang pin serial atau yang sering disebut serial ports dan juga ICSP yang berguna untuk membuat koneksi dengan modul lain yang sesuai. Dengan adanya 4 pasang pin serial, Arduino Mega 2560 dapat melakukan komunikasi secara serial dengan beberapa modul pada suatu sistem yang sama. Arduino Mega 2560 ini membutuhkan tegangan kerja sebesar 5V dan memiliki port untuk memberikan tegangan 3,3V. Arduino Mega 2560 juga dapat menerima tegangan masuk sebesar 7-12V melalui power jack yang telah disediakan. Modul ini memiliki SRAM sebesar 8 KB dan EEPROM sebesar 4KB. Arduino Mega 2560 juga memiliki clock speed sebesar $16 \mathrm{MHz}$.

Program pemroses di mikrokontroler berfungsi untuk mengatur modul relay yang akan menggerakkan katup pada solenoid, mengatur modul AC light dimmer yang akan mengatur output pada lampu dan juga mengatur output dari remot AC. Pada modul pemroses ini mikrokontroler menerima masukkan dari handphone pengguna melalui aplikasi Android berupa data. Masukkan data ini diubah menjadi data high atau low oleh mikrokontroler. Data high yang diterima mikrokontroler digunakan untuk membuka kunci pintu yang berupa solenoid lock, maka mikrokontroler akan mengirimkan sinyal ke relay agar saklar pada relay saling terhubung sehingga tegangan mengalir pada solenoid dan katup pada solenoid akan terbuka. Data low yang diterima mikrokontroler digunakan untuk menutup katup pada solenoid, maka mikrokontroler akan mengirimkan sinyal ke relay agar saklar pada relay saling terpisah sehingga tidak ada tegangan yang mengalir pada solenoid dan katup pada solenoid akan menutup. Potongan program pada Gambar 3.6 digunakan untuk menggunakan tipe data integer pada relay yang di define pada pin nomor 12 pada mikrokontroler dan juga pengiriman data ini menggunakan komunikasi serial dengan nama mySerial yang di define pada pin 10 untuk RX dan pin 11 untuk TX.

SoftwareSerial mySerial $(10,11) ; / / \mathrm{RX}, \mathrm{TX}$

int relay $=12$;

- Gambar 2. Potongan Program Arduino solenoid

Potongan program untuk membuka atau menutup katup pada solenoid dapat dilihat pada Gambar 3. Pada potongan program di Gambar 3 mempunyai fungsi untuk melakukan loop pada saat komunikasi serial available. 
Penerimaan data akan dibaca oleh mySerial.read dan dimasukkan ke dalam variabel temp dengan tipe data char. Apabila mikrokontroler menerima huruf 1 pada variabel temp maka akan membuat katup pada solenoid terbuka dan apabila mikrokontroler menerima huruf A maka akan membuat katup pada solenoid menutup.

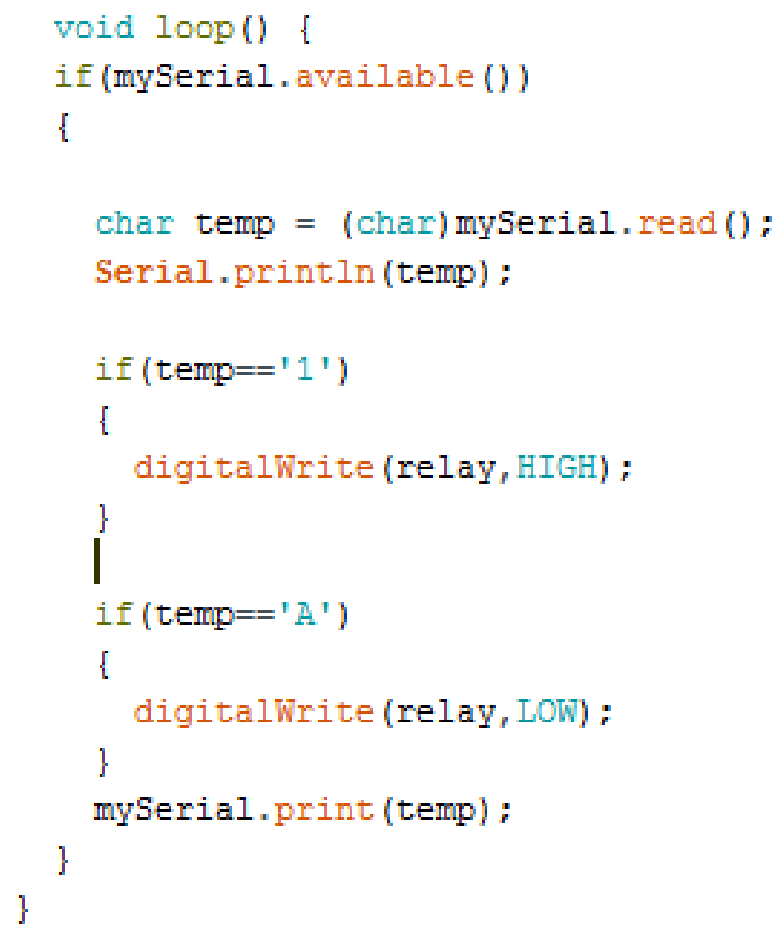

- Gambar 3. Potongan Program Arduino solenoid (1)

Potongan program Arduino pada Gambar 3.8 menjelaskan menggunakan tipe data integer untuk AC_LOAD yang di define pada pin 3 yang berfungsi sebagai output ke lampu dari modul AC light dimmer dan juga menggunakan tipe data integer untuk dimming yang berguna untuk memberikan nilai intensitas pada lampu. Nilai yang diberikan adalah mulai dari 90 (menyala terang) sampai 125 (mati sepenuhnya) melalui aplikasi Android. Pada potongan program ini juga menggunakan interrupt 0 yang di-define pada pin 2 yang berfungsi sebagai function zero_cross_int untuk memberikan nilai RISING pada pin. Nilai baud rate untuk komunikasi serial antara Bluetooth dengan Arduino yang digunakan adalah 9600.

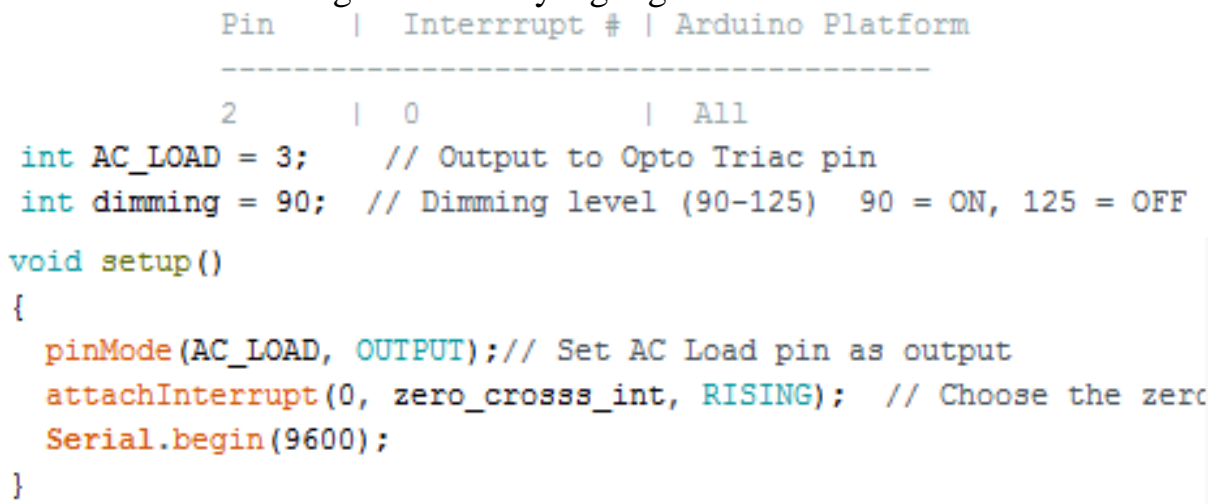

- Gambar 4. Potongan Program Arduino lampu

Potongan program pada Gambar 5 menjelaskan kalkulasi dimtime yang berfungsi sebagai waktu yang dibutuhkan untuk menunggu triac agar aktif dan hasil dari kalkulasi yang digunakan dalam satuan microsecond. Ketika selesai dalam menunggu waktu yang sudah di kalkulasi dari dimtime maka triac akan aktif. Triac kemudian akan menjadi non aktif dari kondisi LOW yang diberikan, nilai low ini berguna untuk menghindari penyalaan triac yang secara tidak sengaja ada siklus selanjutnya, tetapi harus menunggu waktu sekitar 10 microsecond untuk mengetahui triac menyala kembali. 


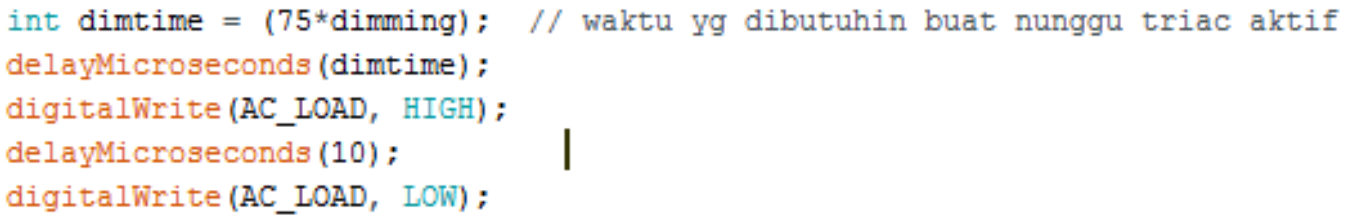

- Gambar 5. Potongan Program Arduino lampu (1)

Pada potongan program arduino lampu yang terakhir yang terdapat pada Gambar 6 mempunyai fungsi untuk melakukan loop pada saat komunikasi serial available, lalu nilai dimming akan diberikan melalui serial read dari aplikasi Android yang sudah disediakan. Nilai yang tersedia adalah 90 hingga 125, yang mana 90 untuk memberikan kondisi lampu menyala terang dan nilai 125 untuk memberikan kondisi lampu mati sepenuhnya. Bila nilai yang diberikan di antara 90 dan 125 akan memberikan kondisi redup sesuai dengan keinginan.

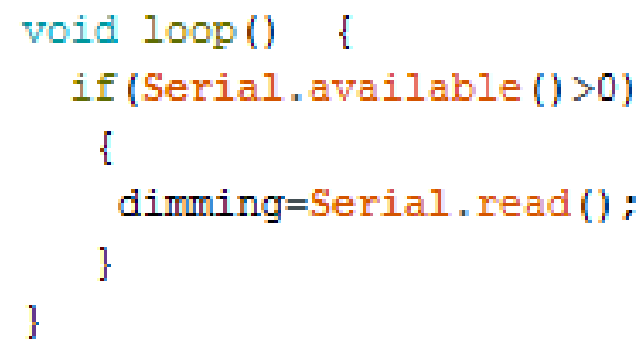

- Gambar 6. Potongan program Arduino lampu (2)

Potongan program pada Gambar 7 digunakan untuk menggunakan tipe data integer pada trans 1 , trans2, trans3, trans 4, dan trans 5. Pada Gambar 3.11 juga menunjukkan pin yang di define untuk setiap variabel-variabel tersebut. Seperti contoh trans 1 di define pada pin 15, trans2 di define pada pin 16, trans 3 di define pada pin 17, trans 4 di define pada pin 18, dan trans 5 yang di define pada pin 19. Variable-variabel yang sudah di define ini berfungsi untuk menggendalikan transistor yang sudah disambungkan kaki collector dan emitter ke common Vcc dan common ground pada PCB remot AC.

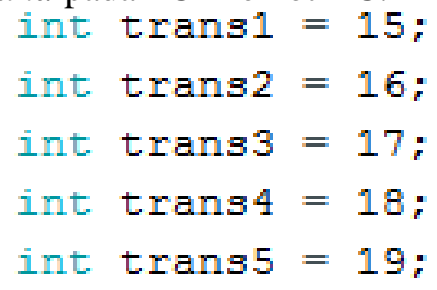

- Gambar 7. Potongan program Arduino remote controller AC

Potongan program pada Gambar 8 mempunyai fungsi untuk mendeklarasikan variabel yang sudah di define sebagai pin output. Nilai baut rate untuk komunikasi serial antara bluetooth dengan Arduino yang digunakan adalah 9600 dengan nama mySerial.

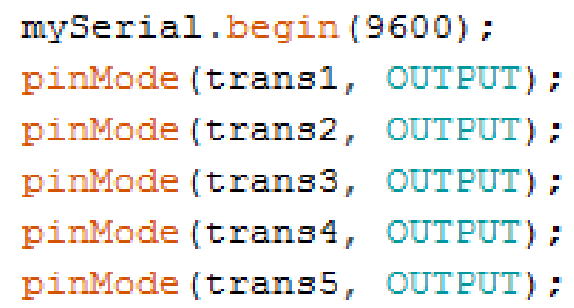

- Gambar 8. Potongan program Arduino remote controller AC (1)

Potongan program pada Gambar 9 digunakan untuk menghubungkan kaki collector yang sudah disambungkan ke common Vcc pada PCB remot AC dengan kaki emitter yang sudah disambungkan ke common ground pada pcb remot AC apabila Arduino menerima angka "2" yang akan memberikan nilai HIGH yang akan menghubungkan kaki emitter dan kaki collector, ketika kaki collector dan kaki emitter terhubung maka seolaholah sedang menekan tombol fisik pada remote controller AC.

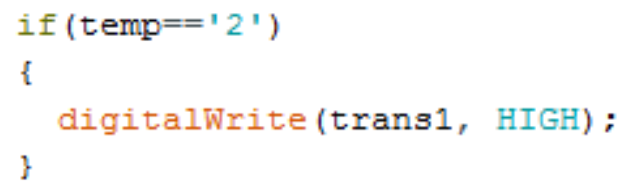


- Gambar 9. Potongan program Arduino remote controller AC (2)

\section{Modul Bluetooth Hc-05}

Bluetooth berfungsi untuk melakukan pengiriman data dari modul pemroses yang dikirim ke modul android. Fitur yang digunakan bluetooth adalah serial RXD, TXD, VCC, dan GND. Koneksi bluetooth yang terhubung dengan mikrokontroler terlihat pada indikator LED. Tegangan input yang digunakan antara 3,3V-5V DC

\section{Modul Relay 12 V}

Pada perancangan ini modul relay digunakan pada solenoid lock sebagai switching. Modul relay ini digunakan karena tegangan yang dikeluarkan mikrokontroler masih belum cukup untuk menggerakkan katup solenoid lock.

\section{Solenoid Lock}

Pada perancangan ini solenoid lock digunakan sebagai pembuka dan pengunci pintu. Alasan menggunakan alat ini karena relatif mudah digunakan dan mudah dicari di pasaran.

\section{Modul Ac Light Dimmer}

Modul AC light dimmer ini terdiri dari beberapa komponen yang dijadikan menjadi satu modul. Komponen-komponen tersebut diantaranya terdapat 3 buah resistor, 1 buah triac, 2 buah diac, 1 buah optocoupler, 2 pin untuk LOAD dan 2 pin untuk AC-IN. Modul ini dapat di kontrol menggunakan mikrokontroler seperti Arduino, Raspberry Pi dan sebagainya. Pada sistem ini digunakan modul AC light dimmer ini karena adanya fitur pin zero crossing detector yang membuat mikrokontroler dapat mengetahui timing yang tepat untuk mengirim sinyal PWM. Tanpa ada nya timing yang tepat, arus AC dengan triac jika gatenya di kontrol makan akan kacau sinyal outputnya yang menyebabkan dimmer tidak berfungsi dalam menghasilkan sinyal PWM. Modul ini dapat bekerja dengan menerima tegangan AC dari $110 \mathrm{~V}$ sampai $220 \mathrm{~V}$.

\section{REALISASI KESELURUHAN SISTEM}

Keseluruhan sistem dilakukan dengan menggabungkan seluruh modul yang dirancang dan yang tidak dirancang. Pengguna terlebih dahulu melakukan pairing bluetooth pada handphone dengan modul bluetooth HC05. Pengguna dapat menghubungkan bluetooth pada handphone dengan modul bluetooth HC-05 setelah melakukan pairing terlebih dahulu. Pengguna dapat menggunakan aplikasi Android yang sudah disediakan yang berfungsi untuk mengendalikan beberapa device seperti lampu, air conditioner, dan juga kunci pintu yang berupa solenoid. Pengguna dapat menekan tombol ON untuk menutup katup pada solenoid dan tombol $\mathrm{OFF}$ untuk membuka katup pada solenoid. Pengguna juga dapat menekan simbol Power untuk menyalakan atau mematikan AC, simbol Arrow UP untuk menaikan temperatur suhu dari AC, simbol Arrow Down untuk menurunkan temperatur suhu dari AC, tombol Fan Speed untuk mengatur kecepatan angin dari AC, dan juga tombol Swing yang berguna untuk menggerakan pengarah angin pada AC secara otomatis atau tidak. Pengguna juga dapat mengendalikan intensitas cahaya dari lampu dengan menggerakkan slider yang tersedia, ketika nilai 90 yang berarti nyala terang dan nilai 125 yang berarti mati. Flowchart cara kerja dari keseluruhan sistem dapat dilihat pada 


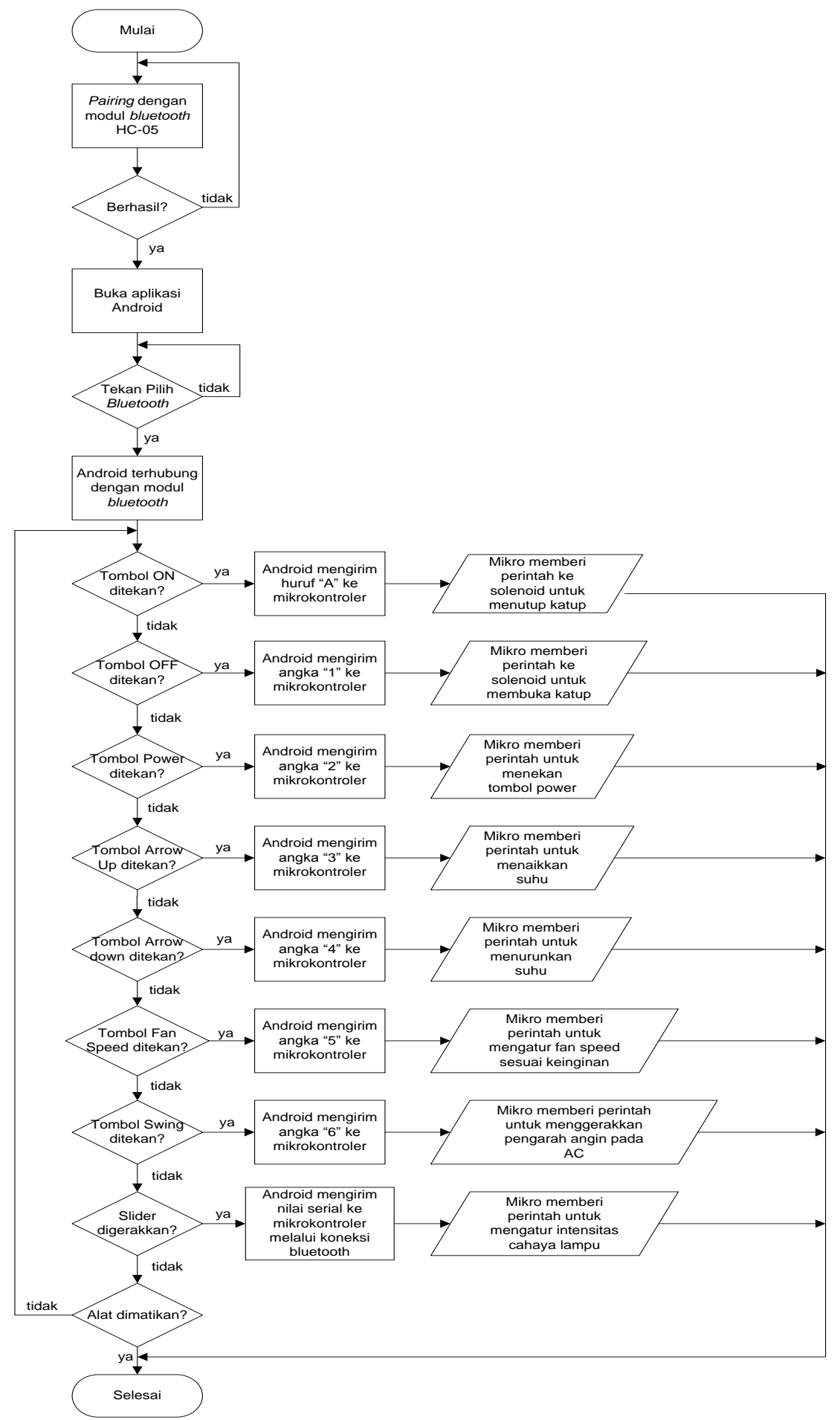

- Gambar 9 Flowchart cara kerja keseluruhan sistem

\section{KESIMPULAN DAN SARAN}

Berdasarkan hasil pengujian sistem keseluruhan, dapat diberikan beberapa kesimpulan dan saran yaitu :

\section{KESIMPULAN}

Kesimpulan yang diperoleh dari sistem kendali lampu, air conditioner, dan kunci pintu berbasis Android adalah sebagai berikut :

a. Dari hasil pengujian, terlihat bahwa pada pengujian modul catu daya dan modul relay terdapat persen kesalahan. Dimana, persen kesalahan modul catu daya adalah $0,34 \%$ dan modul relay $0,22 \%$. Kesalahan tersebut tidak terlalu berpengaruh terhadap kerja alat karena persen kesalahan tidak terlalu besar.

b. Sistem ini dapat dijalankan ketika handphone pengguna dengan modul bluetooth HC-05 berjarak hingga 11 meter. 


\section{SARAN}

Saran yang dapat diberikan untuk pengembangan sistem ini adalah :

a. Membuat sistem pengiriman data menggunakan internet. Karena bila menggunakan jaringan internet, sistem ini dapat dijalankan selama handphone masih terjangkau jaringan internet.

b. Diberikan fitur untuk mematikan sistem secara otomatis guna antisipasi bila pengguna lupa mematikan lampu, air conditioner, atau pun lupa mengunci pintu.

\section{DAFTAR PUSTAKA}

[1] D. Evans, The Internet of Things How the Next Evolution of the Internet Is Changing Everything : Cisco Internet Business Solutions Group (IBSG). San Jose : CISCO, 2011, pp. 2.

[2] Herman. Simulasi Rumah Pintar Dengan Android Sebagai Pengendali. Jurnal TIMES. Vol. IV No 2 (Maret 2015): 45-48.

[3] E. T. Setiawan. Pengendalian Lampu Rumah Berbasis Mikrokontroler Arduino Menggunakan Smartphone. Jurnal TI-Atma STMIK Atma Luhur Pangkalpinang, Februari 2009, 15-25.

[4] A. Fauzan, D. B. Ridwan. Perancangan Prototype Sistem Kendali Lampu Menggunakan Handphone Android Berbasis Arduino. Jurnal PROSISKO. Vol. 1 (September 2014): 35-40.

[5] Herlan. Rangkaian Dimmer Pengatur Iluminasi Lampu Pijar Berbasis Internally Triggered Triac. Jurnal Informatika, Sistem Kendali, dan Komputer. Vol 3 No 1-2 (2009): 20-35.

[6] S. Andri. Alat Kendali Lampu Rumah Menggunakan Bluetooth Berbasis Android. STMIK PalComTech. Jurnal Teknologi Dan Informatika. Vol. 4 No. 1 (Januari 2014): 3-7.

[7] D. Nataliana, I. Syamsu, G. Giantara. Sistem Monitoring Parkir Mobil menggunakan Sensor Infrared berbasis RASPBERRY PI. Teknik Elektro Itenas. Jurnal ElKOMIKA. Vol. 2 No.1 (2014): 1-2.

[8] C. S. Dharma, F. D. Setiaji, D. Santoso. Pengatur Intensitas Lampu Philips Master LED Secara Nirkabel. J. Jurnal Ilmiah Elektroteknika. Vol 11 No 2 (Oktober 2012): 141-150.

[9] A. Apriansyah, Ilhamsyah, T. Rismawan. Prototype Kunci Otomatis Pada Pintu Berdasarkan Suara Penggua Menggunakan Metode KNN (K-Nearest Neighbor). Jurnal Coding Sistem Komputer Untan. Vol 04 No 1 (2016): 45-56.

[10] A. Septryanti, Fitriyanti. Rancang Bangun Aplikasi Kunci Pintu Otomatis Berbasis Mikrokontroler Arduino Menggunakan Smartphone Android. Journal Of Computer Engineering System And Science. Vol 2 No 2 (Juli 2017): 59-63. 